\title{
On the human consequences of terrorism
}

\author{
Daniel G. Arce ${ }^{1}$
}

Received: 9 July 2018 / Accepted: 13 July 2018 / Published online: 1 August 2018

(C) The Author(s) 2018

\begin{abstract}
Terrorist attacks are regarded as low-probability, highly consequential events. What, exactly, are the significant effects of terrorism? This paper presents a cross-sectional depiction of the death and injury profiles for nine of the most violent terrorism tactics: six types of bombings, mass shootings, combined shootings and explosions, and intentional vehicular assaults. By constructing a composite injury and death profile for each tactic under study, terrorist incidents can be ranked in terms of the number of disability adjusted lives lost and disability adjusted life years lost. In addition, the human consequences of terrorism as a whole (on an annual basis) are placed in context relative to the global burden of disease and counterterror expenditures.
\end{abstract}

Keywords Terrorism · Casualties · Injuries · DALYs · Global burden of disease

JEL Classification D74 · F5 · F51

\section{Introduction}

Terrorist attacks are regarded as low-probability, highly consequential events. What, exactly, are the significant effects of terrorism and how are they measured? Terrorism is the use (or threat of use) of violence against civilians and inactive military personnel for the purpose of influencing an audience beyond the immediate victims in order to achieve political, ideological, or religious goals. ${ }^{1}$ The way that terrorism influences its intended audience generally is measured in terms of casualties, electoral consequences, amount of damage at the attack site, and its impact on economic growth and tourism.

Indeed, a general picture of the electoral consequences of terrorism is emerging from cross-country panel data studies. For example, Gassebner et al. $(2008,2011)$ analyze the relationship between terrorism and cabinet duration for more than 800 elections and 115

${ }^{1}$ This definition is an umbrella meant to judiciously capture the definition of terrorism given in Enders and Sandler (2012, p. 4) and the definitions of terrorism used by the US Department of State and the US Department of Defense, as given in Enders and Sandler (2012, p. 6).

Daniel G. Arce

darce@utdallas.edu

1 University of Texas at Dallas, 800 Campbell Rd, GR 31, Richardson, TX 75080, USA 
countries, constituting some 2400 cabinets in total. They find that terrorism increases the statistical likelihood of a cabinet change in the next election. Moreover, the likelihood is positively related to the number of severe events (involving at least one casualty) and the sum of all fatalities during a given year. Such studies examine the effects of domestic and transnational terrorism combined. Two additional cross-country studies focus on the political effects of transnational terrorism alone. Williams et al. (2013) find that when transnational terrorism occurs, parliamentarian governments on the left of the political spectrum are more likely to fail than those on the right, and that the probability of government replacement rises with the total number killed in any given month. Park and Bali (2017) find that transnational terrorism destabilizes incumbents, with the effect being most profound for autocracies.

By contrast, significant difficulties arise when gauging the consequences of terrorism in terms of monetary damages and its effect on economic growth. For example, in the Global Terrorism Database (hereafter, GTD), the value of property damaged by a recorded attack can be missing, indicating that an estimate of the damages was unavailable at the time of the coding of the attack, or recorded as "unknown" (START 2018). If recorded, the reported amount of damages can be quite coarse, e.g., indicating a value less than USD 1 million. Approximately $99.5 \%$ of the terrorism incident entries in GTD leave the property damage associated with an attack blank, or list it as "unknown" or "minor" (likely less than USD 1 million).

Moreover, contrary to the conventional wisdom, it is not possible to infer that terrorism has a statistically significant effect on a country's economic growth, owing to crosssectional interdependence between growth and terrorism with yet-to-be-identified common factors (Gries et al. 2011; Gaibulloev et al. 2014). Granted, some exceptional individual cases exist for which endemic terrorism has had an effect on the overall economy, such as Israel (Laroque et al. 2010), and others for which a particular region has experienced adverse effects, such as the Basque territory in Spain (Abadie and Gardeazabal 2003). With respect to industries, terrorism has an adverse effect on tourism that can spill across borders (Drakos and Kutan 2003). Nevertheless, findings regarding the adverse economic effects of terrorism within a particular region or economic sector do not imply that such findings will prevail for the economy as a whole. Indeed, once panel data estimates are corrected for the fact that economic growth and terrorism are not sufficiently 'distant' in some social, economic, network, spatial, or other sense, Gaibulloev et al.'s (2014) findings convincingly remove the economic growth-terrorism nexus from being considered as a highly consequential effect of terrorism.

Undoubtedly, casualties are what put the "terror" in terrorism. At the same time, very little has been done to assess the human consequences of terrorism beyond counts of the number of deaths and, perhaps, injuries. Indeed, Spagat (2012) notes that, overall, the conflict literature focuses on deaths, likely because of their dramatic consequences, but that more effort needs to be made to measure injuries because they are, "arguably more policy-relevant than deaths, since injuries require ongoing treatment and other policy measures." For example, from 1970 to 2016, domestic and international terrorism combined resulted, on average, in 8338 deaths and 10,785 injuries per year (START 2018). Injuries outnumber deaths across the combination of domestic and transnational terrorist events recorded in GTD, and injuries far outnumber deaths for transnational terrorism alone by approximately a 3:1 ratio (Sandler et al. 2009). For the purposes of this study, measuring the 'human consequences of terror' involves (1) examining what lies beneath these casualty numbers, (2) characterizing how injuries and deaths are distributed according to the most violent tactics employed by terrorists, and (3) comparing and combining injuries and deaths on the same cardinal scale. 
In this way, injuries are placed into context relative to deaths, and terrorism itself can be placed into context in terms of its associated casualties (deaths plus injuries). To contribute to reaching this goal, this paper provides the first cross-sectional depiction of terrorism that accounts for differences in the distribution of injuries across nine types of terrorist attacks: six types of bombings, mass shootings, combined shootings/explosions, and vehicular assaults. ${ }^{2}$ These nine tactics account for $80 \%$ of the deaths and $90 \%$ of the injuries in GTD. In addition, once this profile is created, it is possible to measure the human consequences for each type of tactic and for terrorism as a whole on an annual basis.

Deaths and injuries resulting from terrorism initially were placed in context by Sandler et al. (2009) as part of the Copenhagen Consensus project for prioritizing foreign aid. They used Abenhaim et al.'s (1992) study of the distribution of injuries and posttraumatic stress disorder resulting from 21 terrorist attacks in France between 1982 and 1987 (20 bombings and one machine gun attack) to construct a composite injury profile for a terrorist incident. By associating each type of injury with a disability weight from the Global Burden of Disease (Lopez et al. 2006), Sandler et al. (2009) created an injury profile that is comparable with deaths. This was possible because the disability weight associated with each injury takes a value in the $[0,1]$ interval, with a value of zero being commensurate with optimal health and a value of one corresponding to death. Injuries and deaths therefore are measured on a comparable scale. The product of the number of injured, the proportion of those injured that experience a particular injury, and the disability weight associated with the injury yields the total 'injuries-as-deaths' or 'injuries-as-lives-lost' associated with the injury. Aggregating this calculation over all associated injuries yields the total injuries-asdeaths measure for the attack. In that way, Sandler et al. (2009) estimate that one terrorism injury equates to 0.57 of a death. Subsequently, the 0.57 composite disability weight has been used by Sandler et al. (2011), Enders and Olson (2012), Kaplan (2015), Arvanitidis et al. (2016), Hausken (2018) and Baron et al. (2017) to derive combined measures of terrorism mortality and morbidity.

While novel, the limitations of the approach initiated by Sandler et al. (2009) are twofold. First, the injury profile is based on essentially one form of terrorist attack (bombings) and treats all bombings equally in terms of their injury profiles. Bombings comprise $48 \%$ of the incidents recorded in GTD. Until the present study, very little generally has been known about the effects of terrorism on its immediate victims across attack tactics. That gap is addressed by constructing composite injury and death profiles for six types of terrorist bombings (confined-space, open-space, suicide, vehicle-delivery, structural collapse and structural fire), mass shootings, combined shootings/explosions, and the relatively recent vehicular assaults in crowded areas. For bombings alone the casualty profile depends upon whether the attack takes place in an open or confined space. Given the number of injuries and deaths associated with a specific tactic, the composite disability weight can be used to determine the number of disability-adjusted lives lost (DALLs) associated with the attack. The DALLs can then be used to calculate the disability-adjusted life years (DALYs) lost to terrorist attacks. DALLs and DALYs are combined mortality and morbidity measures developed jointly by the World Bank and World Health Organization (hereafter, WHO) to measure the relative magnitude of healthy lives lost to a disease, injury or mental disorder. Combining the DALLs for the 10,785 yearly average injuries with the average of 8338 lives lost to terrorism yields the (undiscounted) DALYs lost to terrorism.

\footnotetext{
${ }^{2}$ Currently, injury profiles are unavailable for assassinations, hijackings, kidnappings, facility/infrastructure attacks, and unarmed assaults. Those tactics have relatively few casualties.
} 
Second, a counterfactual exists that previously has gone unaddressed. Specifically, although a terrorist attack results in physical injuries and mental disorders, the incidence of these sequelae in the absence of terrorism would not be zero among the survivors. On any given day, someone breaks an arm, experiences moderate hearing loss, gets burned, and so on, or becomes depressed or experiences a traumatic event that leads to posttraumatic stress disorder (hereafter, PTSD). Hence, one must also control for the incidences of injuries and disorders within the general population. For example, if the prevalence of major depressive disorder (hereafter, MDD) among the survivors of a terrorist attack is $25 \%$ (Salguero et al. 2001), and the yearly onset of MDD within the general population is 3.9\% (ESEMeD/MHEDEA 2000 Investigators 2004); among terrorism's survivors an additional $21.1 \%(=25-3.9)$ onset of MDD can be attributed to the attack. Note that only PTSD is included in the Sandler et al. (2009) study.

One contribution of the present paper is that it provides a picture of terrorism not previously available: a summary breakdown of the deaths and injuries associated with nine categories of attack tactics. In creating the first cross-sectional picture of terrorismrelated injuries by attack tactic, the paper identifies an additional dimension for assessing different manifestations of political violence. For example, Conrad and Greene (2015) demonstrate that it is the quality of terror, rather than the quantity, that matters when assessing the "outbidding" theory of competition among terrorist groups. Their analysis is based on categorizing GTD incidents into two ordinal measures of attack quality. The first measure is target severity, with the ranking of severity running in increasing order from (1) infrastructure targets, to (2) combatants (military, police or rival terrorist groups), to (3) citizens, tourists, NGO personnel and the media. The second measure is attack type. Again, in increasing order of severity these measures are (1) infrastructure and unarmed assaults, (2) hostage taking or hijackings, and (3) violent attacks, such as assassinations, armed assaults and bombings. The present analysis illustrates that even those attacks that would qualify as most severe by either ordinal measure differ substantially in terms of cardinal measures of their effects.

An analysis of the nine forms of terrorist attack tactics examined here leads to the following additional results. First, including injuries in the calculation of DALLs increase the human cost of terrorism by more than $50 \%$ compared to deaths alone. Second, comparing DALLs across attack categories allows for a ranking of terrorist incidents in terms of their human consequences. Mass shootings are found to be the most consequential form of attack, with combined shootings/explosions being second. Suicide bombings come in third out of the nine tactics covered. That finding bolsters evidence that suicide bombings receive disproportionate media coverage after adjusting for various characteristics of attacks, including the number of people killed (Jetter 2017). Third, the present study identifies why vehicular assaults should be of increasing concern. Vehicular assaults are both logistically simple and have significantly higher injury and death profiles than many other forms of terrorism. Fourth, the human consequences of terrorism as a whole (on an annual basis) are placed in context relative to the global burden of disease and counterterror expenditures. For example, when the deaths and injuries associated with terrorism are aggregated across attack types, terrorism ranks in the bottom $9 \%$ of the disabilities, injuries, and disorders considered in the Global Burden of Disease (Murray et al. 2012). Terrorism thus is shown to be a low probability event with small consequences, as measured by its global burden. In that way, preexisting work that is circumspect about the risk and effectiveness of terrorism (e.g., Abrahms 2011; Wilson and Thompson 2005) is corroborated using entirely different data and methods for assessing the consequences of terrorism. 


\section{Data}

This study considers only the direct human consequences of a terrorist attack. That is, those individuals who lost their lives, were injured, or experienced mental disorders owing to their physical presence at the site of the attack. Electronic witnesses of the event on television, the internet, or by other means, and the effects on the relatives and households of the direct victims are not considered.

Understanding that caveat, the steps involved in combining terrorism injuries with deaths are as follows. First, identify the frequency of different types of injuries associated with different types of terrorist attacks. Second, map those injuries into the categories that receive disability weights (DWs) in the Global Burden of Disease (Salomon et al. 2015) hereafter, $G B D$. Third, identify the number of injuries associated with a given type of terrorist attack. Fourth, combine steps one, two and three in order to arrive at the number of lives lost due to disability (LDs) associated with each terrorist tactic. Fifth, combine the LDs with the number of lives lost (LLs) associated with a given tactic to arrive at the number of disability adjusted lives lost (DALLs $=$ LLs + LDs) for the tactic. Finally, given the life expectancy of terrorism victims, one can compute the DALYs lost for specific terrorist tactics as well as for terrorism as a whole. Consequently, data are needed on (1) the injury profile for each tactic, (2) the disability weight associated with each type of injury, (3) the number of injuries and deaths associated with each tactic, (4) the age profiles of victims, and (5) years of life expectancy lost to premature death or injury. In addition, in order to provide a counterfactual, the incidence of each type of injury within the general population is needed.

In summary, data are needed to calculate the following:

$\begin{array}{ll}f_{i} & \text { frequency of disability/injury/disorder ' } i, \text { ' where } 0 \leq f_{i} \leq 1 \\ \mathrm{DW}_{i} & \text { disability weight for disability/injury/disorder ' } i, \text { ' where } 0 \leq \mathrm{DW}_{i} \leq 1 \\ \mathrm{LD}_{i} & \text { number of injuries-as-lives-lost to disability/injury/disorder ' } i . \\ \mathrm{LD} & \text { total injuries-as-lives-lost to a terrorist tactic (attack category) } \\ \mathrm{LL} & \text { total lives lost (deaths) to a terrorist tactic (attack category) } \\ \text { DALLs } & \text { total disability adjusted lives lost to a terrorist tactic (DALL=LD+LL) } \\ \text { DALYs } & \text { total disability adjusted life years lost to a terrorist tactic }\end{array}$

In reality, data are exceedingly scarce on the breakdown of injuries resulting from particular types of terrorist attacks. In the major terrorism databases, often all that is recorded is the number of casualties (those killed or injured). Yet data on the associated frequency of injuries, $f_{i}$ 's, are needed to calculate DALLs and DALYs. A contribution of this paper is that it leverages data from multiple sources, typically, epidemiological meta- or multi-year studies of the injury profiles of different terrorist attack tactics. Those profile data are then used to make predictions on the breakdown of injuries by tactic, as, in general, this information is not directly available. The data sources are discussed below, as are the nature of and sources for the disability weights.

\subsection{Injury profile}

The distribution of each type of injury associated with each type of attack is summarized in Table 1. The sources for these data are discussed in this subsection. Injuries are 


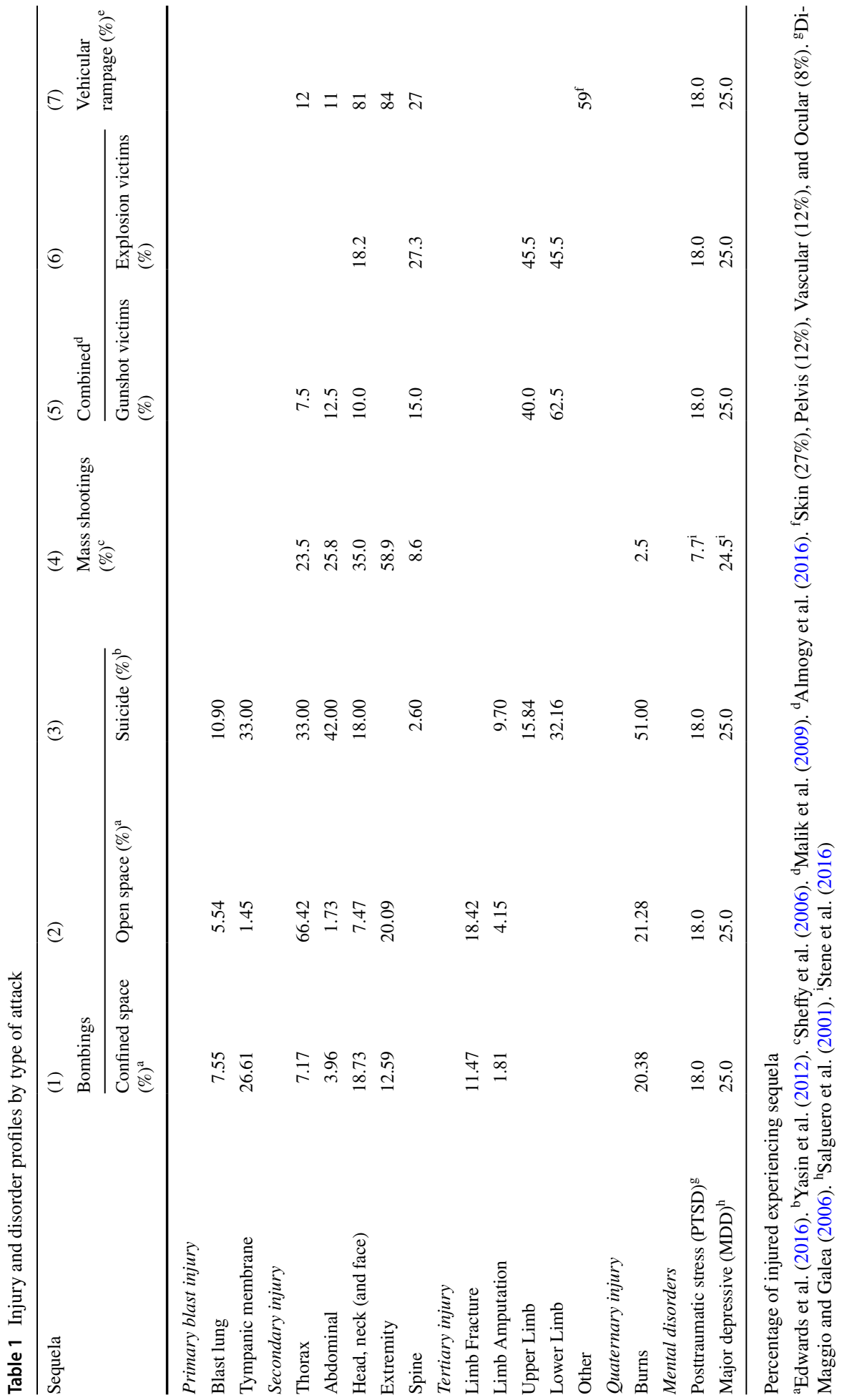


organized as listed in Table 1 because bombing injuries fall into four categories (Edwards et al. 2016): primary blast pressured-induced (blast lung, tympanic membrane), secondary effects of projectiles (thorax, abdominal, head and neck, extremity, spine), tertiary (limb fracture, limb amputation), and quaternary (burns).

In addition, in examining Table 1 it is clear that, for a given tactic, the overall percentage of injuries sustained can sum to a total that is greater than $100 \%$. That is because many victims sustain multiple injuries. Moreover, certain tactics lead to more multiple injuries than other tactics. For these reasons, the occurrence of multiple injuries is important information that should not be arbitrarily ruled out by normalizing injury frequencies so that they sum to $100 \%$ for a given tactic. For example, survivors of vehicular assaults have, in general, been struck by the largest 'projectile' — a vehicle — and sustain more multiple injuries than any other form of terrorist tactic considered here. For vehicular assaults, the sum of the frequency of all injuries in column (7) of Table 1 is $274 \%$. Multiple injuries clearly are a consequence of vehicular assaults. The method used for dealing with multiple injuries when calculating DALYs is addressed below.

Edwards et al. (2016) conduct a meta-study of the injury profiles of 167 terrorist bombings worldwide from 1970 to 2014. In so doing, they find significant differences in the injury profile for bombings taking place in open versus confined spaces. For example, the primary (pressure-induced) injuries associated with bombings increase within confined areas because of the effects of reflections or reverberations of the blast from walls or other structures (DePalma et al. 2005). By contrast, open-space bombings do not result in a great degree of primary blast injuries because the associated pressure dissipates in the absence of fixed boundaries. Such differences can be seen by comparing the primary blast data rows in columns (1) and (2) of Table 1. The injury profile for suicide bombings in column (3) comes from a different data source. Yasin et al. (2012) provide information from a 3-year study of 1296 multiple injuries from suicide bombing victims hospitalized in Rawalpindi, Pakistan. Their study is relied on because the injury categorization is comparable to that in Edwards et al. (2016). Suicide bombings differ significantly from conventional bombings in terms of both their mortality and injury profiles (Hicks et al. 2011; Santifort-Jordan and Sandler 2014).

Comprehensive accounts of injuries sustained in terrorist mass shootings are given in Peleg et al. (2004), Sheffy et al. (2006) and Turner et al. (2016). Turner et al. (2016) is a meta-study of 17 mass casualty shootings worldwide during 1980-2016. Their study is not restricted to terrorist incidents, whereas Peleg et al. (2004) and Sheffy et al. (2006) are studies of terrorism-related mass shootings in Israel. Only the Israeli studies include information on the types of injuries sustained, with the injury classifications in Sheffy et al. (2006) being the most comparable to the other analyses herein. Sheffy et al.'s (2006) data, which covers 2000-2004 and 553 victims, are given in the fourth column of Table 1. Interestingly, the overall death rate of $33.3 \%$ in Sheffy et al. (2006) is exactly that given for mass-casualty shootings in Turner et al. (2016).

Incidents during which terrorists used a combination of firearms and explosives in a public place include the 60-h 2009 attack in Mumbai and the Paris concert area attack of November 2015. Malik et al. (2009) provide injury data for an attack within a mosque in Quetta, Pakistan on 4 July 2004 with 94 victims in which $78.5 \%$ of the injuries resulted from gunshot wounds and the remaining $21.5 \%$ from explosives. Given that the injury categories in Malik et al. (2009) are comparable in detail to the other studies employed here, their data are used for attacks that combine gunshots and explosives. See columns (5) and (6) of Table 1 . Note that the numbers actually are below the casualty counts for the attacks in Mumbai (Bhandarwar et al. 2012) or Paris (Gregory et al. 2016). 
Finally, during 2016-2017, a rash of vehicular assaults occurred in which a terrorist intentionally drove a moving vehicle into an area crowded with pedestrians, such as a market or bridge. Unfortunately, Israel has had significant prior experiences with that specific tactic. In particular, Almogy et al. (2016) provide injury data for 29 intentional vehicular assaults in Jerusalem from October 2008 to May 2016. Assaults by driven vehicles inflict the greatest number of multiple injuries on survivors, as detailed in column (7) of Table 1.

\subsection{Mental disorders}

In addition to physical injuries, survivors of terrorist attacks are known to experience mental disorders such as PTSD and MDD. PTSD occurs at about double the rate in survivors of terrorist attacks than in survivors of motor vehicle accidents (Shalev and Freedman 2005). In their meta-study of 113 articles on the behavioral consequences of terrorism worldwide, DiMaggio and Galea (2006) find that an average of $18 \%$ of terror survivors experience PTSD. Salguero et al.'s (2011) meta-study of 736 direct terror victims finds that $25 \%$ experience MDD. Those proportions are assumed to hold across all columns/types of terrorist attacks in Table 1, with the exception of mass shootings [column (4)]. For that column, the findings reported in Stene et al. (2016) for the survivors of the mass shooting in Utøya, Norway on 22 July 2011 are used. Their figures are 7.7\% for PTSD and 24.5\% for MDD. All of the data for PTSD and MDD apply to persistence of the disorder for at least 1 year following the attack.

\subsection{Disability weights}

In order to compare injuries with lives lost, each injury category in Table 1 requires a disability weight $(D W)$. For each injury, ' $i, D W_{i} \in[0,1]$. That method allows injuries and lives lost to be expressed in a comparable cardinal scale. For example, hearing loss often is associated with bombings. In Table 2, the row labeled "tympanic membrane" gives the disability weight associated with moderate hearing loss as 0.027 and that for profound hearing loss as 0.204 . The health state of an individual is $1-D W_{i}$. Consequently, an individual with profound hearing loss experiences $1-0.204=76.9 \%$ of optimal health, whereas one with moderate hearing loss experiences $1-0.027=97.3 \%$ of optimal health. Disability weights are regarded to be constant across countries for a given injury/disease/disorder.

First determined in 1990 by the World Bank and WHO, the values of disability weights are obtained from a panel of judges and are meant to reflect the relative desirability of a health state for a given clinical description of a disability, injury, or disorder (Haagsma et al. 2014). Choice-based methods that panelists use to assess health states include standard gamble and time tradeoff (Brazier et al. 2017). An assessment for the panel as a whole is derived from statistical analyses of individual panelist's responses. In the standard gamble, a panelist is given a choice between (a) living in the health state associated with ' $i$,' for the last $h$ years of his or her life, or (b) submitting to a medical procedure that will be fully restorative for those $h$ years but carries a probability, $p_{i}$, of immediate death. Various tradeoff exercises involving different values of $p_{i}$ are presented in order to assist a panelist in selecting a value of $p_{i}$ that induces indifference between options (a) and (b). A time tradeoff elicitation process facilitates the panelists' identification of the number of years of perfect health, $y_{i}$, that would make them indifferent to $h$ years in health state ' $i$,' where $y_{i}<h$. In addition, methods exist for distinguishing panelists' confounding factors, such as risk aversion from $p_{i}$, and rate of time preference from $y_{i}$. 


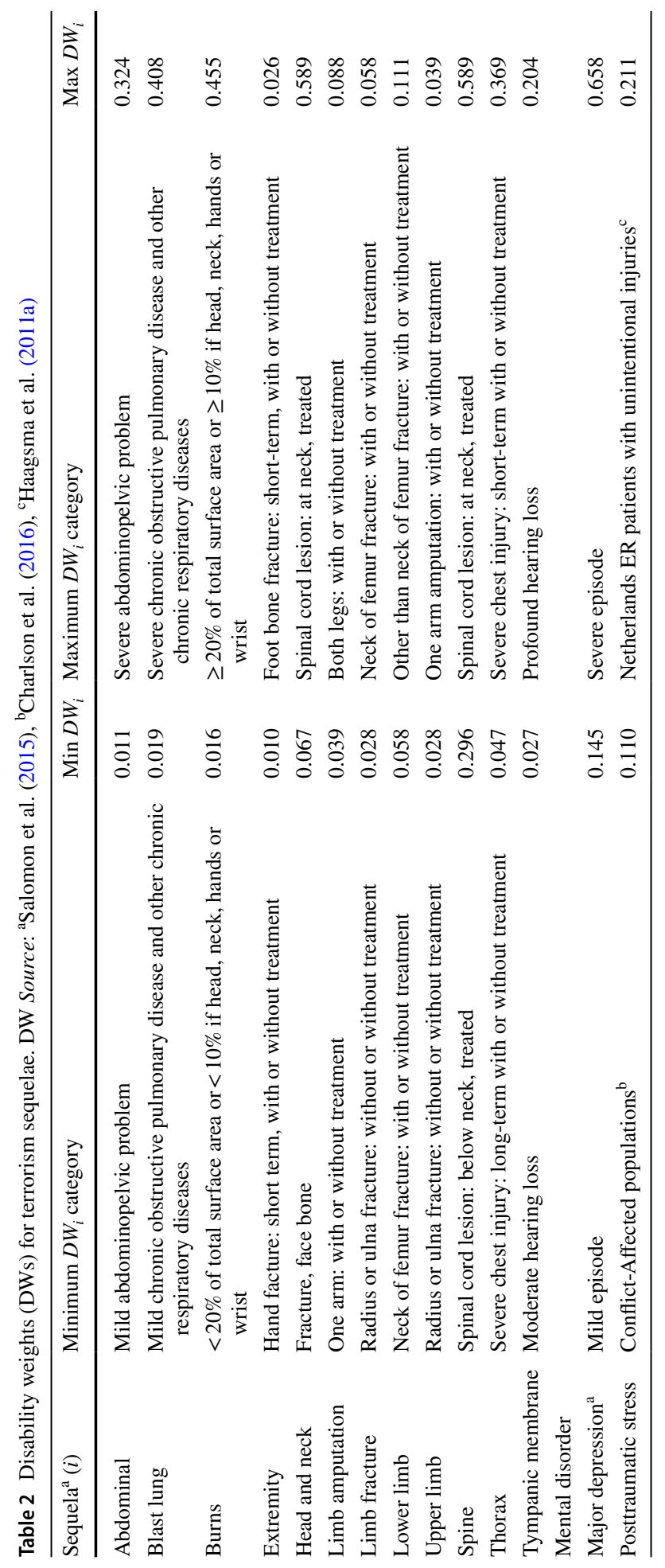


Finally, health state values are rescaled to lie between 0 and 1 and turned into the associated disability weight. The disability weight is calculated as 1 -health state value, specifically for standard gamble, $D W_{i}=p_{i}$, and for time tradeoff, $D W_{i}=1-y_{i} / h$. It is important to keep in mind that one cannot simply invert those formulas in order to arrive at an alternative tradeoff-based interpretation of the disability weight in terms of $p_{i}$ or $y_{i}$. As they are not measured in terms of epidemiological data (such as incidence or prevalence), disability weights are a means to an end. In this study, the disability weights are used in combination with the frequency of a particular disability/injury/disorder for a terrorist tactic in order to arrive at summary measures of the associated health consequences (DALLs and DALYs). These in turn will be used to measure the human consequences of terrorism.

Unfortunately, many of the injuries in Table 1 do not have an exactly corresponding disability category in $G B D$. For that reason a range of minimum and maximum values for each injury is considered, as detailed in Table 2. The ranges for the number of lives lost owing to disability (LDs) for different types of terrorist attacks are calculated by using the minimum disability weights given in Table 2 and then again by using the maximum disability weights in the same table. In that way, a range of LDs is calculated for each tactic. In addition, at present $G B D$ does not contain disability weights for PTSD. The PTSD disability weights derived in Charlson et al. (2016) and Haagsma et al. (2011a) are used for the minimum and maximum values, respectively.

\subsection{Casualties}

The deaths and injuries for each tactic are presented in the upper section (first two rows) of Table 3. Arnould et al. (2004) report median deaths and injuries for six different types of bombings using worldwide data covering 43 events. They are the data entered in the first two rows of columns (1)-(6). The sources for deaths and injuries in columns (7)-(9) have been discussed above. Note that the Arnould et al. (2004) bombing study is for mass-casualty events involving 30 or more casualties; hence, it is a study of 'spectaculars' and that feature must be kept in mind. At the same time, the bombings are being compared to data for mass shootings and combined shootings/explosions, both of which are mass casualty tactics, by definition. A comparison is therefore being made across spectacular versions of those tactics. ${ }^{3}$ The first two rows of Table 3 must therefore be understood as an upperbound estimate of the human consequences of terrorism.

In comparing the categories it is easy to see that suicide bombings cause more casualties than any other type of bombing. By comparison, mass shootings and combined gunshot/explosion attacks cause more casualties than suicide bombings. Combined attacks are logistically complex; therefore, they are inherently designed to produce mass casualties.

\section{Lives lost to terrorism injuries}

The imputed number of lives lost to disability/injury/disorder ' $i$ ', $\mathrm{LD}_{i}$, is calculated as follows. Given the associated disability weight, $D W_{i}$, and number of individuals with the sequela, $N_{i}$, $\mathrm{LD}_{i}=D W_{i}^{*} N_{i}$. For specific terror events, the number of individuals with a particular sequela, $N_{i}$, generally is not known. Instead, what is known is the total number of injured, $N$, and the

\footnotetext{
${ }^{3}$ A 'spectacular' representation of recent intentional vehicular assaults is derived in Table 4 below.
} 


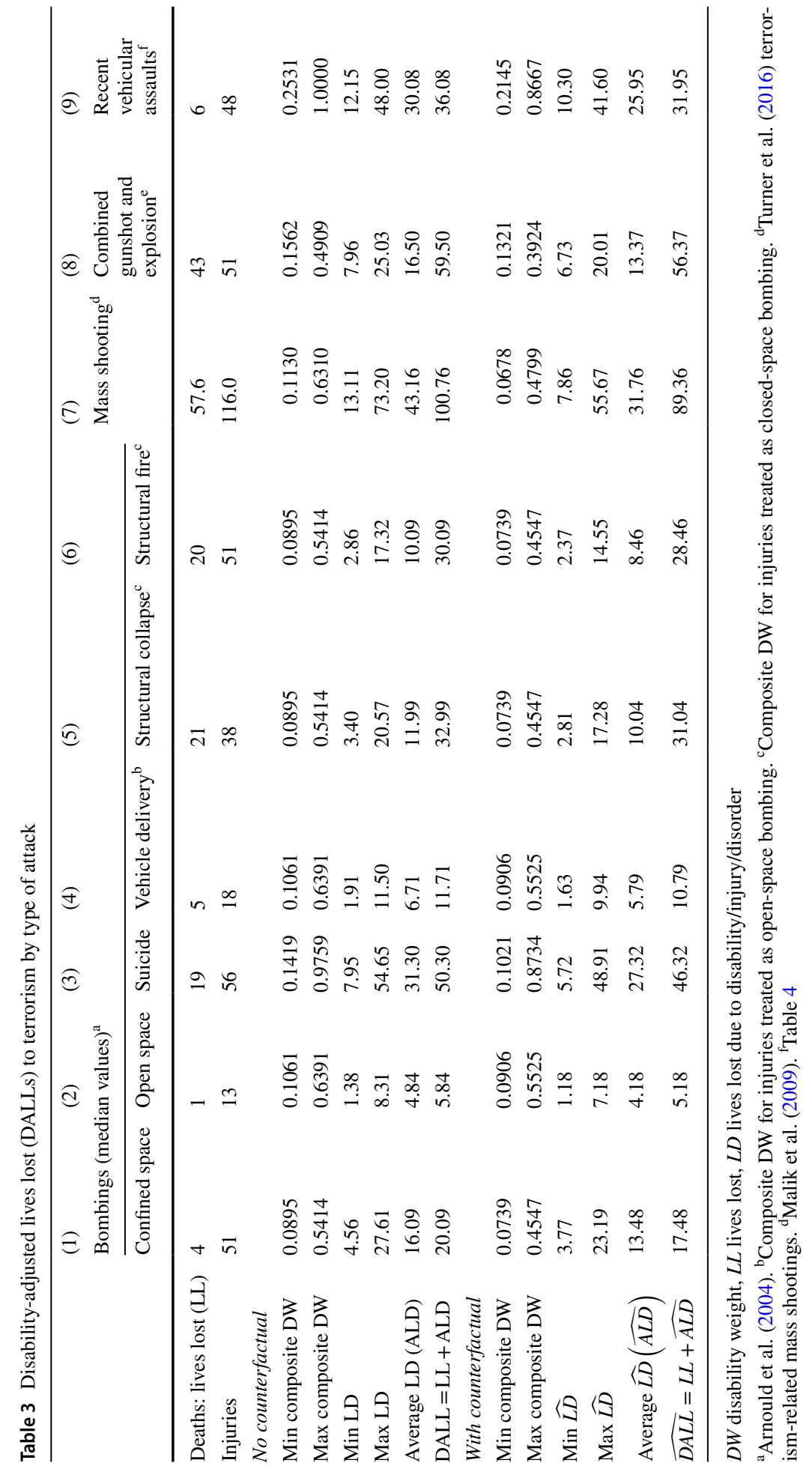




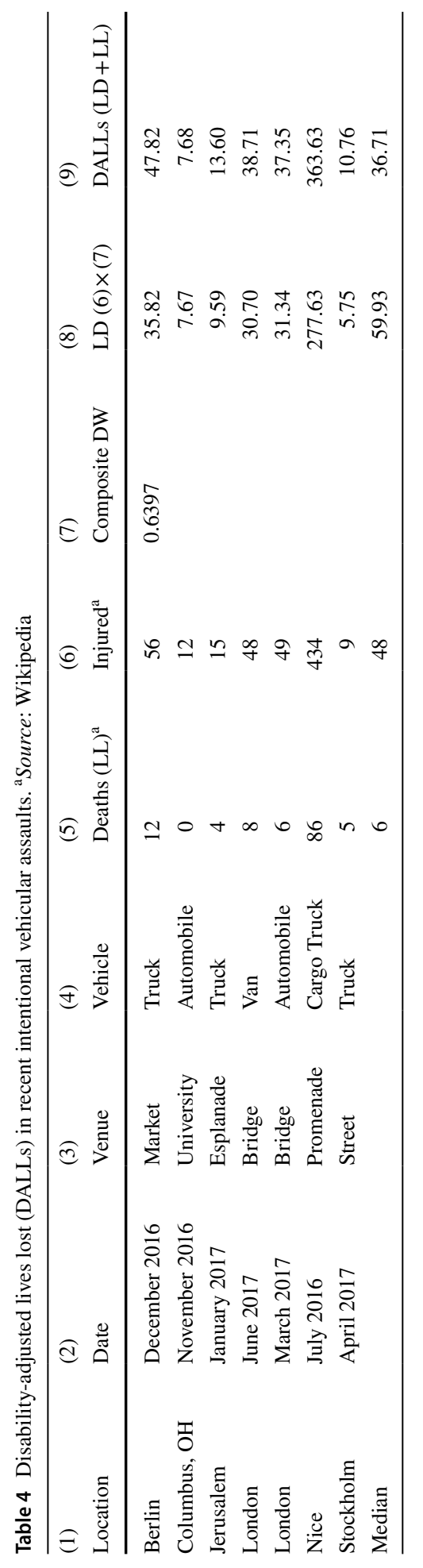


frequency of a particular sequela, $f_{i}$, provided for the first time in Table 1 . Consequently, $N_{i}=f_{i}^{*} N$. It follows that $\mathrm{LD}_{i}=D W_{i}^{*} f_{i}^{*} N$.

Many terror survivors experience multiple injuries. Two primary methods are available for addressing comorbidity across injuries (Mathers et al. 2006; Haagsma et al. 2011b). One method is to assume that the total disability weight is the sum of the separate disability weights. For the additive method, $D W_{i+j}=D W_{i}+D W_{j}$. An alternative approach is to realize that the health state of an individual experiencing sequela ' $i$ ' is $1-D W_{i}$. If one assumes that experiencing combined sequela is more severe than experiencing either on its own, this is akin to the health state values, $1-D W_{i}$ and $1-D W_{j}$ being multiplicative. Hence, the associated disability weight for the multiplicative method is $D W_{i^{*} j}=1-\left(1-D W_{i}\right)^{*}\left(1-D W_{j}\right)$. The multiplicative method has the advantage that it is always the case that $D W_{i^{*} j} \in[0,1]$, whereas for the additive method it is possible that $D W_{i+j}>1$ (death). This contingency is addressed below.

Given the total number of types of injuries, $I$, associated with a particular tactic, the aggregate LD for the tactic when using the additive method is:

$$
\mathrm{LD}=D W_{1} * f_{1} * N+D W_{2} * f_{2} * N+\cdots+D W_{I} * f_{I} * N=N * \underbrace{\sum_{i \in I} D W_{i} * f_{i}}_{\text {Composite } D W^{+}} .
$$

For any given tactic, the associated LD will vary with the number of injured, $N$. Hence, what is common for calculating the lives lost to disability for a specific tactic is the term $\sum_{i \in I} D W_{i} * f_{i}$. That term defines the composite disability weight, $D W^{+}$, for a given tactic when using the additive method to account for comorbidity. Consequently, if the number of injuries for a given terrorist attack is known and the tactic is one of the nine types analyzed here, then the composite disability weight provided by this study can be used to determine the LD for the attack. Such an example is given below for the 2016-2017 spate of intentional vehicular assaults.

Disability weights for individual injuries fall in the $[0,1]$ interval. By definition, the frequency values for a specific injury ' $i$ ', $f_{i}$, also lie within the same interval. However, owing to the presence of multiple injuries, it is possible that the sum $\sum_{i \in J} f_{i}>1$. For example, for vehicular assaults the sum of the injury frequencies is 2.74 , meaning that it is also theoretically possible for the composite disability weight to be greater than one. Yet it must be the case that the composite disability weight takes a value that is less than or equal to one because a value of one corresponds to death. Consequently, when using the additive method, if the composite disability weight for an attack type exceeds one, I reduce the disability weight to a value of one. In this study there is one and only one instance of that phenomenon: the composite disability weight for vehicular assaults when the maximum disability weight is used for each type of injury (see Table 3).

A composite disability weight can alternatively be calculated by applying the multiplicative method to the disability weights for each injury. Specifically,

$$
L D=N * \underbrace{\left[1-\prod_{i \in I}\left(1-D W_{i} * f_{i}\right)\right]}_{\text {Composite } D W^{*}},
$$


where $\Pi$ is the product operator. The composite disability weight using the multiplicative method to account for comorbidity is denoted as $D W^{*}$. It is always the case that $0 \leq D W^{*} \leq 1$.

A comparison of composite disability weights for the additive and multiplicative comorbidity methods is given in the appendix (Table 8) for different types of terrorist attacks. When the minimum disability weights for injuries are used, the two methods are quite close, with an average absolute difference of 0.0090 across the attack types. For the maximum disability weights, they are further apart, with an average absolute difference of 0.1809. Given that Haagsma et al. (2011b) find that the interclass correlation coefficient between observed and predicted comorbidity disability is highest for the additive approach, the additive composite disability weight, $D W^{+}$, will be used in all calculations from this point forward.

Finally, in calculating LD no adjustment is made for duration of injury because LD already is biased downward for several reasons. First, the injury frequencies reported in the studies cited in Table 1 are only for those survivors who were hospitalized. The number of injured and their injuries therefore are both undercounted. Second, it is known that large numbers of non-victims suffer psychologically in the aftermath of a terrorist event. In a meta-study of that phenomenon, Salguero et al. (2001) find that the risk of MDD in nonvictims after a terrorist attack lies between 4 and $10 \%$ for the adult population where the event occurred. Lastly, Kerridge et al. (2012) find evidence that terrorism can have negative effects on public health beyond sequela experienced by the immediate victims and that effect is not accounted for. ${ }^{4}$

It follows that, given the number of lives lost, LL, the number of disability adjusted lives directly lost in a terrorist event is:

$$
\mathrm{DALL}=\mathrm{LL}+\mathrm{LD} .
$$

The difference between DALLs and DALYs is that no adjustment has yet been made for the years of life expectancy lost by the terrorism victims, $Y$. Given $Y$, the (undiscounted) years lived with disability, YLD, is $\mathrm{YLD}=\mathrm{LL}^{*} Y$ and the (undiscounted) years of life lost due to death, YLL, is YLL $=\mathrm{LL} * Y$. The formula for (undiscounted) disability adjusted life years, DALY $=$ YLL + YLD, can therefore be expressed as

$$
\mathrm{DALY}=\mathrm{YLL}+\mathrm{YLD}=\mathrm{LL} * Y+\mathrm{LD} * Y=(\mathrm{LL}+\mathrm{LD}) * Y=\mathrm{DALL} * Y .
$$

Finally, the counterfactual to an injury associated with a terrorist event is not no injury. Many of the injuries - and especially the mental disorders-observed following terrorist incidents also occur in the population at large. As such, one has to consider the frequency of injury ' $i$ ' within the population (per 100 persons), $\hat{f}_{i}$. Consequently, the counterfactual net frequency of injury ' $i$ ' is $f_{i}-\hat{f}_{i}$. Given this counterfactual, the net lives lost to disability ' $i$ ' are

$$
\widehat{L D}_{i}=N_{i} * D W_{i} *\left(f_{i}-\hat{f}_{i}\right) .
$$

The frequency of an injury per 100 persons, $\hat{f}_{i}$, can be extremely low. In order to avoid scientific notation, injury frequencies are commonly reported on a per 10,000 or 100,000 person basis. For example, $\hat{f}_{i}$ is zero for primary blast injuries because, "bombs and explosions cause unique patterns rarely seen outside of combat" (CDC 2016). By contrast, the

$\overline{{ }^{4} \text { See Ghobarah et al. (2003) for the effects of civil war on public health. }}$ 
onset of mental disorders within the general population during a 12-month period is substantial. The ESEMeD/MHEDEA 2000 Investigators (2004) put the 12-month onset of MDD at $3.9 \%$ for adult Europeans and for PTSD they put it at $0.9 \%$. The implication is that if $25 \%$ of the survivors of a terrorist bombing experience MDD, this actually is a net increase of $21.1 \%\left(f_{i}-\hat{f}_{i}=25-3.9\right)$ that can be attributed to the terrorist event. Similarly, the $18 \%$ who experience PTSD represent an attributable net increase of $17.1 \%(=18-0.9)$. The data for the counterfactual calculations are given as an appendix (Table 9).

\section{Results}

The casualties for nine different types of terrorist attacks are displayed in the first two rows of columns (1)-(9) of Table 3. Examining those two rows alone makes it clear that attack tactics vary substantially in terms of both the distribution and numbers of deaths and injuries.

\subsection{Composite disability weights for terror attacks}

The middle section of Table 3 begins with the composite disability weights, where the term 'composite' means that the disability weight is an aggregation of the frequency of injuries sustained for a given type of terrorist attack. At this point, no attempt is made to control for the counterfactual, which is the frequency of the injuries in the general population in the absence of terrorism. In calculating the composite disability weight, either the minimum disability weight values for all injuries are used or the maximum disability weight values are used (refer to Table 2). For example, as measured by the composite disability weight, each injury sustained in a confined-space bombing ranges between 0.0895 and 0.5414 of a life lost. The finding of one injury equating to 0.57 of a life lost by Sandler et al. (2009) falls just outside that range but it does fall within the range of 0.1061-0.6391 of a life lost for open-space bombings. Suicide bombings cause injuries that range between 0.1419 and 0.9759 of a life lost [column (3)]. The composite disability weight in column (7) for mass shootings ranges between 0.113 of a life lost to 0.631 . For attacks that combine gunshots/explosives, the range for disability weights is $0.1562-0.4909$. Intentional vehicular assaults, which have become increasingly popular with Islamic State-inspired terrorists, lead to injuries that range from 0.2531 to 1.0 of a life lost.

When the composite disability weight is multiplied by the number of injuries, the result is the number of lives lost due to disability. This is then added to the number of lives lost to determine the number of DALLs for a given type of terrorist attack. By comparing DALLs one can see that, on average, the form of terrorist attack with the greatest human consequences is mass shooting, with a DALL of 100.76. The second-most consequential form of terrorism is an attack that combines shootings/explosions (DALL $=59.50$ ). Mass shootings are twice as consequential as suicide bombings $(\mathrm{DALL}=50.30)$, which is the third highest form of attack analyzed here. The lower ranking of suicide bombings should not be surprising given Jetter's (2017) recent findings that, (1) "suicide attacks receive more media coverage purely for being suicide attacks," even when controlling for deaths, and (2) in terms of media coverage, a suicide attack is equivalent to an alternative attack that generates 95 deaths. Hence, suicide attacks should not be expected to be at the top of the DALLs ranking because the suicide aspect substitutes for casualties as a means of gaining media attention. 


\subsection{Controlling for the counterfactual}

The bottom section of Table 3 controls for the counterfactual that, in the absence of a terrorist event, some of the victims would still have experienced an injury or mental disorder. On average, the effect of this counterfactual is to reduce the composite disability weight for conventional bombings by $15 \%$, suicide bombings by $12.7 \%$, mass shootings by $26.4 \%$, attacks that combine shootings/explosions by $18.95 \%$, and vehicular assaults by $13.7 \%$. Controlling for this counterfactual has a qualitatively significant impact on the composite disability weights.

\subsection{Application to vehicular assaults}

The methodology introduced above can be used to assess the recent rash of vehicle assaults, as indicated in Table 4. "Following the (vehicular assault) attack in Nice that killed 86 people in July 2016, the Islamic State published a guide for would-be attackers, noting that vehicles are 'extremely easy to acquire' and unlikely to arouse the suspicions of citizens or authorities" (Clarke and Klarevas 2017). That characterization of vehicular assaults is more in line with the spectacular nature of the casualties given for the first eight tactics in Table 3. The recent vehicular assaults have a median DALL of 36.71, making them the fourth-most consequential form of terror attack relative to the DALL calculations in Table 3. Given the logistical ease of intentional vehicular assaults, and their associated consequences when conducted at the scale currently experienced, this is likely a harbinger of the future of terrorism.

\section{The human consequences of terrorism in context}

The purpose of DALYs is to provide a summary measure of the relative burden (healthy life years lost) for different diseases, bodily injuries and mental disorders. The data and methodology introduced above allow for a determination of the burden of a terrorist attack, as measured by DALYs. Undiscounted DALYs are equal to the product of disability adjusted life years and the years of life expectancy lost by the victims: $\mathrm{DALY}=\mathrm{DALL}^{*} Y$. The value used for years of life expectancy lost, $Y$, is the number of years of life expectancy lost for the median or mean age of terror victims. Once again, a range of values is considered. Specifically, in Stene et al. (2016) the mean age of the victims of the Utøya mass shooting was approximately 19 years old. Almogy et al. (2016) report a mean age of 24.7 for vehicular assaults in Israel. For the Oklahoma City bombing in the United States, Mallonee et al. (1996) give a median age of 39. In addition, for an attack to be truly representative of the civilian population, it is assumed that $50 \%$ of the victims are female. Life expectancy data for each country come from the World Bank.

The DALY ranges for individual types of attack are given in Table 5. The injury counterfactual is not applied there, as DALYs are most often presented without accounting for the counterfactual, and the DALYs for terrorism will be compared with those associated with other phenomena. The DALYs for an individual type of attack range from 368 to 6348 years. As is the case for DALLs, the form of terrorist attack with the largest DALY is mass shootings, followed by combined shootings/explosions, suicide bombings and the recent spate of intentional vehicular assaults. 


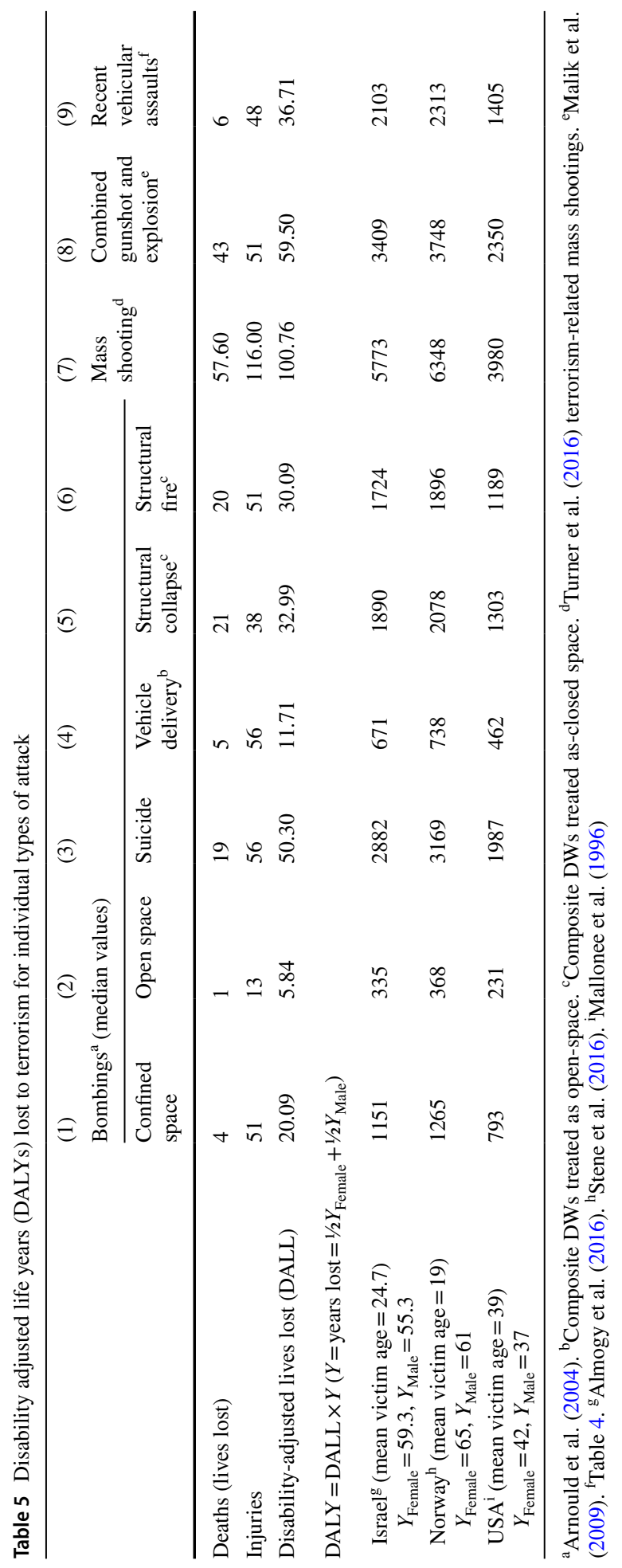




\subsection{The global burden of terrorism}

In order to estimate the burden of terrorism for a particular year, consider the following exercise. Using the GTD dataset, 8338 terrorism-related deaths occur per year (1970-2016). In addition, 10,785 terrorism-related injuries occur annually. These totals are given in the final column of Table 6 . As Table 6 is comparing aggregates, rather than individual tactics, the deaths and injury data come from GTD rather than from the first two rows of Tables 3 or 5. Deaths and injuries are allocated to each tactic according to a normalized percentage of total deaths and injuries within GTD among the nine tactics. For example, suicide bombings constitute $16.86 \%$ of the deaths within the nine types of attack examined herein, and $22.53 \%$ of the injuries. Combined shootings/explosions constitute $15.47 \%$ of the deaths and $9.5 \%$ of the injuries; vehicular assaults constitute $1.04 \%$ of the deaths and $3.39 \%$ of the injuries. GTD distinguishes between suicide and non-suicide bombings, but does not further refine bombings into closed-space, open-space, vehicle delivery and structural collapse categories. Hence, non-suicide bombings, which constitute $23.64 \%$ of the deaths and $52.23 \%$ of the injuries, are assumed to fall uniformly across those four tactics (5.91\% of the deaths and $13.06 \%$ of the injuries each).

The results of this exercise are presented in Table 6. By accounting for injuries, the annual average of 8338 lives lost to terrorism is increased to 12,628 disability adjusted lives lost. That represents a $51 \%$ increase in the measured number of lives lost to terrorism annually. By contrast, the annual DALYs for terrorism as a whole range from 502,056 to 798,984, with a median value of 726,695 . That number is an extremely low health burden for disease. If terrorism were a disease, injury, or mental disorder, its DALY would rank in the bottom decile of the 291 diseases and injuries included in the Global Burden of Disease (Murray et al. 2012). Specifically, in Table 7 it is shown that terrorism would rank 266th, i.e., in the bottom $9 \%$. Relative to the diseases that plague mankind, terrorism has limited consequences.

\subsection{The counterterror context}

Counterterror expenditures ultimately are designed to save lives and this study quantifies the casualties attributable to terrorism. Moreover, recall that Gaibulloev et al. (2014) use a panel dataset to show that it is unlikely that terrorism has a significant effect on economic growth. In addition, the data on damages is so coarse that $99.5 \%$ of the entries in GTD provide no specific property damage figures, with $76 \%$ of the total listed as "unknown" or left blank. Hence, the immediate consequences of terrorism primarily are human, consistent with the focus of this paper.

Consider, therefore, the following calculation. The September 11th Victim Compensation Fund was tasked with determining compensation for the families of the people killed by the events of $9 / 11$. The average award for a death claim ended up being approximately $\$ 2$ million (Feinberg 2006). During the same period, US public spending on homeland security alone rose from $\$ 20.1$ billion per year in 2001 to $\$ 54.3$ billion per year in 2005 (Hobijn and Sager 2007). Taking $\$ 2$ million per life as a benchmark, those figures work out to federal money spent to save roughly 27,000 lives per year $(\approx \$ 54.3 / \$ 2 \mathrm{~m}) .^{5}$ The calculation is consistent with the following well-known statement contained in the 911 Commission Report (US Congress 2002): "terrorists need to be successful only once to kill Americans

\footnotetext{
5 GTD does not provide data on foiled attempts or plots because an "attack must actually be attempted to qualify for inclusion in the database" (START 2018).
} 


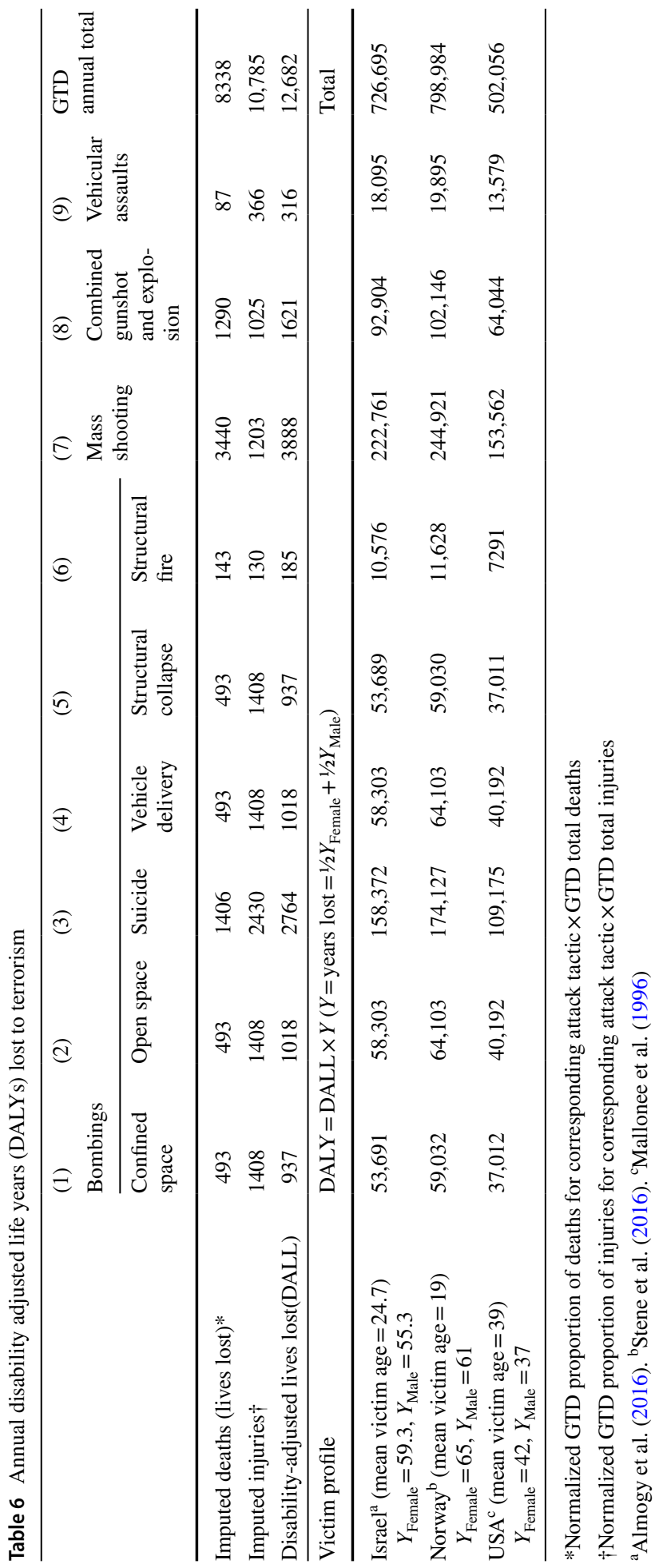


Table 7 Terrorism and the global burden of disease

\begin{tabular}{lll}
\hline Rank & Disease & DALYs $^{\text {a }}$ (thousands) \\
\hline 1 & Ischemic heart disease & 129,820 \\
2 & Lower respiratory infections & 115,277 \\
$\vdots$ & & \\
260 & Animal contact (non-venomous) & 929 \\
261 & Thyroid cancer & 836 \\
262 & Dengue & 825 \\
263 & Vitamin A deficiency & 806 \\
266 & Non-melanoma skin cancer & 798 \\
265 & Inguinal or femoral hernia & 791 \\
& Terrorism & 727 \\
266 & Sexually transmitted chlamydial diseases & 714 \\
267 & Other gynecological diseases & 705 \\
268 & Hodgkin's disease & 647 \\
269 & Trichomoniasis & 638 \\
$\vdots$ & &
\end{tabular}

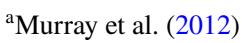

and demonstrate the inherent vulnerabilities they face." By contrast, a total of 12,628 disability adjusted lives are lost to terrorism annually worldwide, of which but a fraction are US citizens, implying a benefit-cost ratio no greater than $0.47(=12,628 / 27,000)$. Granted, disability weights and DALYs have been designed with allocative efficiency of health interventions in mind, but this level of inefficiency does give one pause as to the underlying rationale for counterterrorism expenditures.

\section{Conclusion}

This paper provides the first cross-sectional picture of the human consequences of terrorism by type of attack tactic. In particular, it presents the injury and mental disorder profiles for nine types of terrorist attacks: confined-space bombings, open-space bombings, suicide bombings, vehicle delivered bombings, structural collapses due to bombings, structural fires due to bombings, mass shootings, attacks that combine shootings/explosions and vehicular assaults. The tactics found to be responsible for the most casualties, as measured by disability adjusted lives lost, are mass shootings, followed by combined shootings/ explosions, suicide bombings, and the recent phenomenon of vehicular assaults.

The rankings presented herein are possible because composite disability weights are also derived for each type of attack, which facilitates getting past counts of the numbers of deaths and injuries alone, presenting a clearer picture of the human consequences of terrorism. Examining terrorism through the lens of casualties (deaths + injuries) leads to 
a different ranking of terror tactics than ranking by deaths alone. In addition, the ability to combine deaths and injuries into one useful measure prevents injuries from being viewed as separate from or incomparable to deaths, thereby providing a comprehensive overall portrait of the effects of terrorism on its victims. For example, instead of observing 8388 deaths and 10,785 terrorism-related injuries annually due to terrorism, it is now possible to state that there are 12,682 disability-adjusted lives lost annually to terrorism. This is a 51\% increase in the average number of deaths attributed to terrorism absent the injury count. It also removes ambiguity regarding how to place injuries in context.

At the same time, the impact of terrorism is placed into context against two standards. For a representative year, the median number of disability adjusted life years lost to terrorism is 486,378 . That is, terrorism lies in the bottom $9 \%$ of the global burden of disease. Similarly, it is shown that the benefit-cost ratio for DHS counterterror expenditures can be no greater than 0.47 .

That calculation suggests that a significant portion of counterterror expenditure is noninstrumental, i.e., a public spending rationale that includes something other than its effect on terrorists. For example, cross-country panel analyses suggest that terrorism increases the statistical likelihood of cabinet changes in parliamentary governments, implying that counterterror policy has a role to play as a form of organizational and/or coalitional maintenance for those currently holding power. Indeed, Coates et al. (2006) show that the distribution of DHS funds among US states can be partly explained by the electoral votes per capita of a state, rather than being more directly tied to each state's vulnerability to terrorism. Research is therefore needed into the fundamental tension between the instrumental and political goals of counterterror policy. In this sense, counterterror policy's ends may not differ substantially from those of terrorism itself, which also has non-instrumental rationales geared towards maintaining terrorist organizations.

Finally, the data and techniques presented herein allow for a much more thorough treatment of the effects of terrorism injuries beyond their use as count data. The injury profile data assembled herewith can better prepare emergency rooms for the types of injuries likely to be admitted in the immediate aftermath of a given type of terrorist attack. In addition, the cost of injuries has been expressed in terms of deaths. An alternative measure would be the cost of treatment, which presumably differs for blast lung injuries versus broken femurs versus major depressive disorders, etc. Moreover, it is much more likely that the degree to which terrorism acts as system stressor, such as on public health, is explained by the diversion of resources to the injured, rather than to those killed, because the treatment and care of the injured is ongoing, and is not limited to healthcare professionals.

Acknowledgements I am grateful to Rodney Andrews, Martin Gassebner, Juanita Haagsma, Todd Sandler, Michael Spagat, and two anonymous referees for helpful comments, and Fiona Charlson for a useful email exchange. In addition, Dongfang Hou provided valuable research assistance. Any errors are my own.

Open Access This article is distributed under the terms of the Creative Commons Attribution 4.0 International License (http://creativecommons.org/licenses/by/4.0/), which permits unrestricted use, distribution, and reproduction in any medium, provided you give appropriate credit to the original author(s) and the source, provide a link to the Creative Commons license, and indicate if changes were made.

\section{Appendix}

Tables 8 and 9 . 


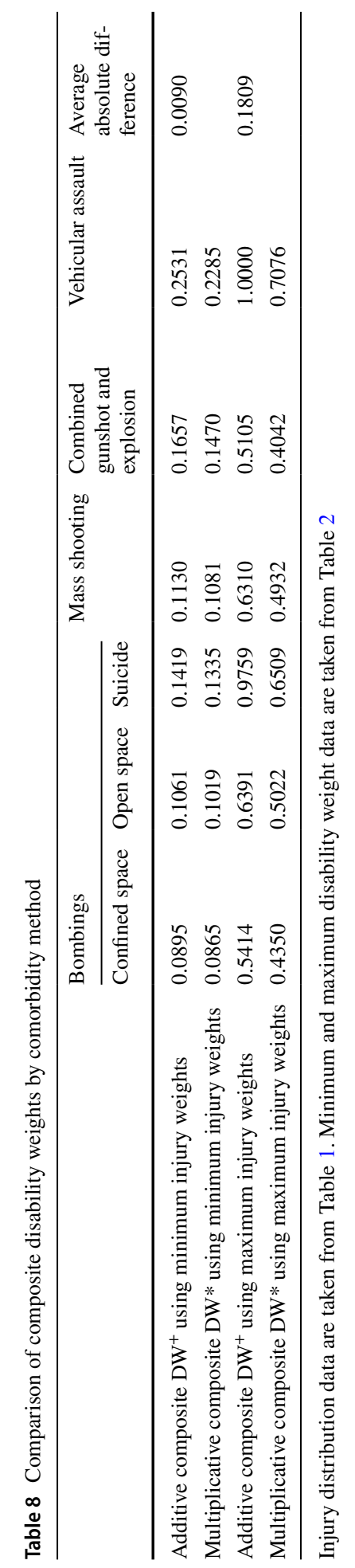




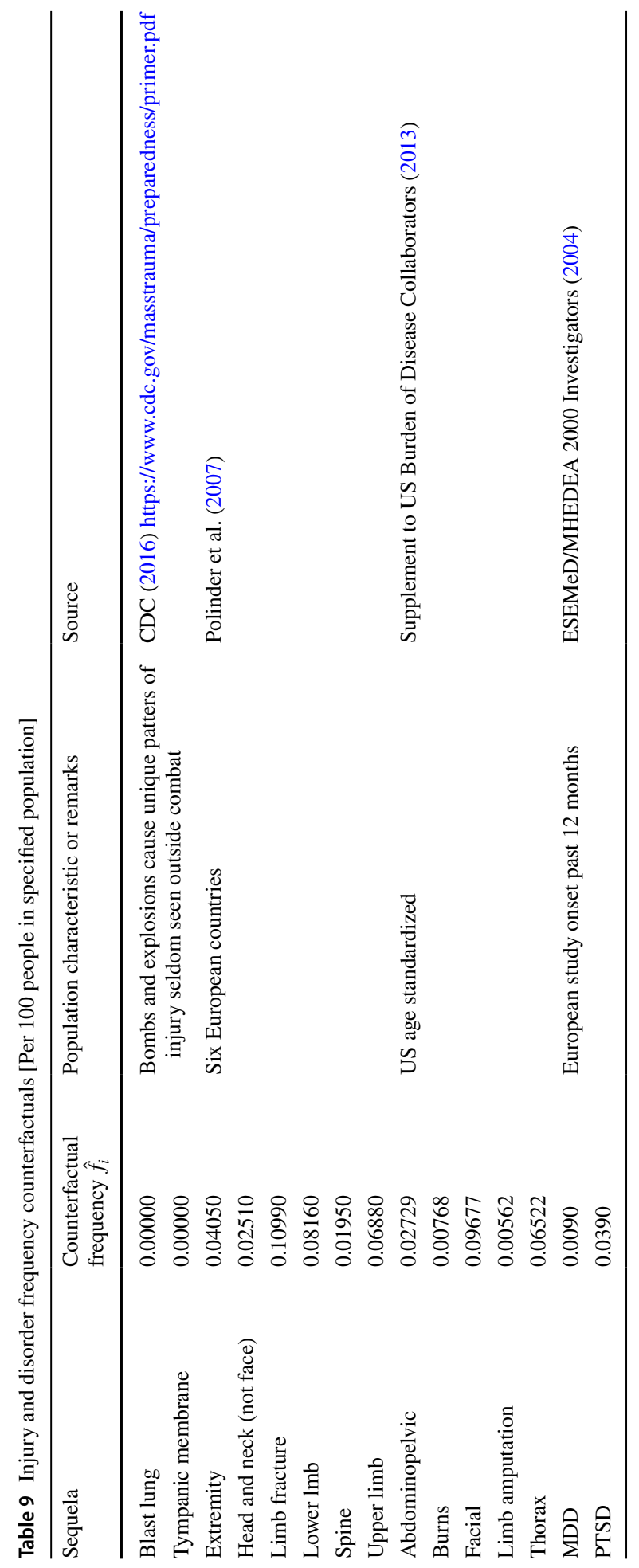




\section{References}

Abadie, A., \& Gardeazabal, J. (2003). The economic costs of conflict: A case study of the Basque Country. American Economic Review, 93(1), 113-132.

Abenhaim, L., Dab, W., \& Salmi, L. R. (1992). Study of civilian victims of terrorist attacks (France 1982-1987). Journal of Clinical Epidemiology, 45(2), 103-109.

Abrahms, M. (2011). Does terrorism really work? Evolution in the conventional wisdom since 9/11. Defence and Peace Economics, 22(6), 583-594.

Almogy, G., Kedar, A., \& Bala, M. (2016). When a vehicle becomes a weapon: Intentional vehicle assaults in Israel. Scandinavian Journal of Trauma, Resuscitation and Emergency Medicine, 24(1), $149-153$.

Arnould, J. L., Halpern, P., Tsai, M.-C., \& Smithline, H. (2004). Mass casualty terrorist bombings: A comparison of outcomes by bombing type. Annals of Emergency Medicine, 43(2), 263-273.

Arvanitidis, P., Economou, A., \& Kollias, C. (2016). Terrorism's effects on social capital in European countries. Public Choice, 169(3), 231-250.

Baron, O., Berman, O., \& Gavious, A. (2017). A game between a terrorist and a passive defender. Production and Operations Management, 27(3), 433-457.

Bhandarwar, A. H., Bakhshi, G. D., Tayade, M. B., Borisa, A. D., Thadeshwar, N. R., \& Gandhi, S. S. (2012). Surgical response to the 2008 Mumbai terror attack. British Journal of Surgery, 99(3), $368-372$.

Brazier, J., Ratcliffe, J., Solomon, J. A., \& Tuschiya, A. (2017). Measuring and valuing health benefits for economic evaluation (2nd ed.). Oxford: Oxford University Press.

Centers for Disease Control. (2016). Explosions and blast injuries. A primer for clinicians. https://www.cdc. gov/masstrauma/preparedness/primer.pdf. Accessed 5 July 2018.

Charlson, F. J., Flaxman, A. L., Ferrari, A. J., Vos, T., Steel, Z., \& Whiteford, H. A. (2016). Post-traumatic stress disorder and major depression in conflict-affect populations: An epidemiological model and predictor analysis. Global Mental Health, 3(January), 1-11.

Clarke, C. P., \& Klarevas, L. (2017). London and the mainstreaming of vehicular terror. The Atlantic, 4 June, https://www.theatlantic.com/international/archive/2017/06/london-bridge-terrorism-attac k/529116/. Accessed 20 July 2017.

Coates, R. M., Karahan, G., \& Tollison, R. D. (2006). Terrorism and pork-barrel spending. Public Choice, $128(1-2), 275-287$.

Conrad, J., \& Greene, K. (2015). Competition, differentiation, and the severity of terrorist attacks. Journal of Politics, 77(2), 546-561.

DePalma, R. G., Burris, D. G., Champion, H. R., \& Hodgson, M. J. (2005). Blast injuries. New England Journal of Medicine, 352(March), 1335-1342.

DiMaggio, C., \& Galea, S. (2006). The behavioral consequences of terrorism: A meta-analysis. Academic Emergency Medicine, 13(5), 559-566.

Drakos, K., \& Kutan, A. M. (2003). Regional effects of terrorism on tourism in three Mediterranean countries. Journal of Conflict Resolution, 47(5), 621-641.

Edwards, D. S., McMenemy, L., Stapley, S. A., Patel, H. D. L., \& Clasper, J. C. (2016). 40 years of terrorist bombings-A meta-analysis of the casualty and injury profile. Injury International Journal of the Care of the Injured, 47(3), 646-652.

Enders, W., \& Olson, E. (2012). Measuring the economic costs of terrorism. In M. R. Garfinkel \& S. Skaperdas (Eds.), The Oxford handbook of the economics of peace and conflict (pp. 363-387). Oxford: Oxford University Press.

Enders, W., \& Sandler, T. (2012). The political economy of terrorism (2nd ed.). Cambridge: Cambridge University Press.

ESEMeD, MHEDA 2000 Investigators. (2004). Prevalence of mental disorders in Europe: Results from the European study of the epidemiology of mental disorders (ESEMeD) project. Acta Psychiatrica Scandinavica, 109(Suppl. 420), 21-27.

Feinberg, K. R. (2006). What is life worth?. New York: PublicAffairs.

Gaibulloev, K., Sandler, T., \& Sul, D. (2014). Dynamic panel analysis under cross-sectional dependence. Political Analysis, 22(2), 258-273.

Gassebner, M., Jong-A-Pin, R., \& Mierau, J. O. (2008). Terrorism and electoral accountability: One strike, you're out. Economics Letters, 100(1), 126-129.

Gassebner, M., Jong-A-Pin, R., \& Mierau, J. O. (2011). Terrorism and cabinet duration. International Economic Review, 52(4), 1253-1270.

Ghobarah, H. A., Huth, P., \& Russett, B. (2003). Civil wars kill and maim people-Long after the shooting stops. American Political Science Review, 97(2), 189-202. 
Gregory, T. M., Bihel, T., Guigui, P., et al. (2016). Terrorist attacks in Paris: Surgical trauma experience in a referral center. Injury International Journal of the Care of the Injured, 47(10), 2122-2126.

Gries, T., Krieger, T., \& Mierrieks, D. (2011). Causal linkages between domestic terrorism and economic growth. Defence and Peace Economics, 22(5), 493-508.

Haagsma, J., Polinder, S., Cassini, A., Colzani, E., \& Havelaar, A. H. (2014). Review of disability weight studies: Comparison of methodological choices and values. Population Health Metrics, 12, 20.

Haagsma, J., Polinder, S., Toet, H., et al. (2011a). The effect of comorbidity on health-related quality of life for injury patients in the first year following injury: Comparison of three comorbidity adjustment approaches. Population Health Metrics, 9, 10.

Haagsma, J., Van Beeck, E. F., Polinder, S., et al. (2011b). Beyond the neglect of psychological consequences: Post-traumatic stress disorder increases the non-fatal burden of injury by more than $50 \%$. Injury Prevention, 17(1), 21-26.

Hausken, K. (2018). A cost-benefit analysis of terrorist attacks. Defense and Peace Economics, 29(2), $111-129$.

Hicks, M. H.-R., Dardagan, H., Bagnall, P. M., Spagat, M., \& Sloboda, J. A. (2011). Casualties in civilians and coalition soldiers from suicide bombings in Iraq, 2003-2010: A descriptive study. The Lancet, 378(9794), 906-914.

Hobijn, B., \& Sager, E. (2007). What has homeland security cost? An assessment: 2001-2005. Current Issues in Economics and Finance, Federal Reserve Bank of New York, 13(2), 1-7.

Jetter, M. (2017). More bang for the buck: Media coverage of suicide attacks. Terrorism and Political Violence. https://doi.org/10.1080/09546553.2017.1288112.

Kaplan, E. (2015). Socially efficient detection of terror plots. Oxford Economic Papers, 67(1), 104-115.

Kerridge, B. T., Khan, M. R., \& Sapkota, A. (2012). Terrorism, civil war, one-sided violence and global burden of disease. Medicine, Conflict and Survival, 28(3), 199-218.

Laroque, D., Lincourt, G., \& Normandin, M. (2010). Macroeconomic effects of terrorist shocks in Israel. Defence and Peace Economics, 21(4), 317-336.

Lopez, A. D., Mathers, C. D., Ezzati, M., Jamison, D. T., \& Murray, C. J. L. (Eds.). (2006). Global burden of disease and risk factors. Washington, DC: The World Bank.

Malik, Z. U., Salim, M., Pervez, M., Hanif, M. S., Tariq, M., Massod, T., et al. (2009). Management of gunshot and blast injuries after a suicidal terrorist attack in a closed space. The Journal of Pakistan Orthopaedic Association, 21(1), 55-61.

Mallonee, S., Shariat, S., Stennies, G., Waxweiler, R., Hogan, D., \& Jordan, F. (1996). Physical injuries and fatalities from the Oklahoma City bombing. Journal of the American Medical Association, 276(5), 382-387.

Mathers, C. D., Iburg, K. I., \& Begg, S. (2006). Adjusting for dependent comorbidity in the calculation of health life expectancy. Population Health Metrics, 4, 4.

Murray, C. J. L., Vos, T., Lozano, R., et al. (2012). Disability-adjusted life years (DALYs) for 291 diseases and injuries in 21 regions, 1990-2010: A systematic analysis for the global burden of disease study 2010. The Lancet, 380, 2195-2224.

Park, J., \& Bali, V. (2017). International terrorism and the political survival of leaders. Journal of Conflict Resolution, 6(17), 1343-1370.

Peleg, K., Aharonson-Daniel, L., Stein, M., Michaelson, M., Kluger, Y., Simon, D., et al. (2004). Gunshot and explosion injuries. Characteristics, outcomes, and implications for care of terror-related injuries in Israel. Annals of Surgery, 239(3), 311-318.

Polinder, S., Meerding, W. J., Mulder, S., Petridou, E., van Beeck, E., \& EUROCOST Reference Group. (2007). Assessing the burden of injury in six European countries. Bulletin of the World Health Organization, $85,27-34$.

Salguero, J. M., Fernandez-Berrocal, P., Iruarrizaga, I., Cano-Vindel, A., \& Galea, S. (2001). Major depressive disorder following terrorist attacks: A systematic review of prevalence, course and correlates. BMC Psychiatry, 11(June), 96-106.

Salomon, J. A., Haagsma, J. A., Davis, A., et al. (2015). Disability weights for the global burden of disease 2013 study. The Lancet Global Health, 3, e712-e723.

Sandler, T., Arce, D. G., \& Enders, W. (2009). Transnational terrorism. In B. Lomborg (Ed.), Global crises, global solutions (2nd ed., pp. 516-562). Cambridge: Cambridge University Press.

Sandler, T., Arce, D. G., \& Enders, W. (2011). An evaluation of Interpol's cooperative-based counterterrorism linkages. Journal of Law and Economics, 54(1), 78-110.

Santifort-Jordan, C., \& Sandler, T. (2014). An empirical study of suicide terrorism: A global analysis. Southern Economic Journal, 80(4), 981-1001.

Shalev, A., \& Freedman, S. (2005). PTSD following terrorist attacks: A prospective evaluation. American Journal of Psychiatry, 162(6), 1188-1191. 
Sheffy, N. Y., Mintz, A., Rivkind, I., \& Shapira, S. C. (2006). Terror-wound injuries: A comparison of gunshot wounds versus secondary-fragments-induced injuries from explosives. Journal of the American College of Surgeons, 203(3), 297-303.

Spagat, M. (2012). Estimating the human costs of war: The sample survey approach. In M. R. Garfinkel \& S. Skaperdas (Eds.), Oxford handbook of the economics of peace and conflict (pp. 318-340). Oxford: Oxford University Press.

START (National Consortium for the Study of Terrorism and Responses to Terrorism). (2018). Global terrorism database (Data file). https://www.start.umd.edu/gtd. Accessed 31 May 2018.

Stene, L. E., Wentzel-Larsen, T., \& Dyb, G. (2016). Healthcare needs, experiences and satisfaction after terrorism: A longitudinal study of survivors from the Utøya attack. Frontiers of Psychology, 7: Article 1809.

Turner, C. D. A., Lockey, D. J., \& Rhen, M. (2016). Pre-hospital management of mass casualty civilian shootings: A systematic literature review. Critical Care, 20(1), 362-372.

US Burden of Disease Collaborators. (2013). Supplemental content for: The state of US health: 1990-2010. Burden of disease, injuries and risk factors. Journal of the American Medical Association, 310(6), 591-608.

US Congress. (2002). Joint inquiry into intelligence community activities before and after the terrorist attacks of September 11, 2001. Washington, DC: Senate Report No. 107-351, House Report No. 107-792.

Williams, L. K., Koch, M. T., \& Smith, J. M. (2013). The political consequences of terrorism: Terror events, casualties, and government duration. International Studies Perspectives, 14(3), 343-361.

Wilson, N., \& Thompson, G. (2005). Deaths from international terrorism compared with road crash deaths in OECD countries. Injury Prevention, 11(6), 332-333.

Yasin, M. M. A., Nasreen, G., \& Malik, S. A. (2012). Injury pattern of suicide bomb attacks in Pakistan. European Journal of Trauma and Emergency Surgery, 38(2), 119-127. 